\title{
Possível contribuição da doença periodontal para o desenvolvimento do Alzheimer: uma revisão bibliográfica
}

\author{
Possible contribution of periodontal disease to the development of Alzheimer's: a \\ bibliographic review
}

Posible contribución de la enfermedad periodontal al desarrollo de la enfermedad de Alzheimer: revisión bibliográfica

Victor Hugo Ferrante Maia Athayde ${ }^{1 *}$, Daniel Lopes Marques de Araújo1, Fredson Silva Mendes Júnior $^{1}$, João Lucas Pereira Mariano ${ }^{1}$, Geovanna Versiani de Britto Brandão ${ }^{1}$, Gabriela Fonseca Marçal $^{1}$, Matheus Garcia Ribeiro ${ }^{1}$, Maria Eugênia Costa Casagrande ${ }^{1}$, Talitha Araújo Velôso Faria ${ }^{1}$.

\section{RESUMO}

Objetivo: Encorajar a comunidade científica a realizar estudos mais específicos e concretos que visem associar a doença periodontal ao surgimento do Mal de Alzheimer. Revisão bibliográfica: Dentre as várias causas do Alzheimer, este estudo destaca a sua possível relação com a doença periodontal. Em primeiro plano, as bactérias causadoras da periodontite acarretam uma resposta inflamatória sistêmica exacerbada pelas células de defesa do indivíduo, por conseguinte, esse quadro inflamatório facilita o desenvolvimento do Mal de Alzheimer em pessoas susceptíveis e amplifica os efeitos deletérios dos portadores da demência. Ademais, o acesso das bactérias ao córtex cerebral através do nervo trigêmeo e a consequente liberação de citocinas pró-inflamatórias constitui um mecanismo pelo qual a periodontite pode se relacionar com 0 desenvolvimento do Mal de Alzheimer. Outrossim, o tratamento precoce da doença periodontal pode evitar o desenvolvimento da Doença de Alzheimer. Considerações finais: Portanto, essa revisão mostra que a Doença de Alzheimer e a Periodontite podem possuir uma relação patogênica, contudo mais estudos precisam ser realizados para que esse fato seja estabelecido cientificamente.

Palavras-chave: Mal de Alzheimer, Periodontite, Bactérias, Inflamação.

\begin{abstract}
Objective: To encourage the scientific community to carry out more specific and concrete studies aimed at associating periodontal disease with the onset of Alzheimer's disease. Bibliographic review: Among the various causes of Alzheimer's disease, this study stands out the possible relationship with periodontitis. Firstly, the bacteria causing periodontal disease carries a systemic inflammatory response exacerbated by the individual's defense cells, therefore, this inflammatory condition facilitates the development of Alzheimer's in susceptible people and amplifies the deleterious effects of people with dementia. Furthermore, the access of bacteria to the cerebral cortex through the trigeminal nerve and the consequent release of pro-inflammatory cytokines is a mechanism by which Periodontitis can be related to Alzheimer's disease. Further, the early treatment of periodontal disease can prevent the development of Alzheimer's disease. Final consideration: Thus, this review shows that Alzheimer's disease and Periodontitis can have a pathogenic relationship, however more studies need to be produced for this fact to be scientifically established.
\end{abstract}

Key words: Alzheimer disease, Periodontitis, Bacteria, Inflammation.

${ }^{1}$ Centro Universitário Atenas (Uniatenas), Paracatu - MG.
${ }^{\star}$ E-mail: victorferrante@hotmail.com

SUBMETIDO EM: 5/2021 


\section{RESUMEN}

Objetivo: Animar a la comunidad científica a realizar estudios más específicos y concretos dirigidos a asociar la enfermedad periodontal con la aparición de la enfermedad de Alzheimer. Revisión bibliográfica: Entre las diversas causas de la enfermedad de Alzheimer, este estudio destaca su posible relación con la periodontitis. En primer plano, las bacterias que causan la Enfermedad Periodontal provocan una respuesta inflamatoria sistémica agravada por las células de defensa del individuo, por tanto, esta condición inflamatoria facilita el desarrollo de la enfermedad de Alzheimer en personas susceptibles y amplifica los efectos deletéreos de las personas con demencia. Además, el acceso de las bacterias a la corteza cerebral a través del nervio trigémino y la consiguiente liberación de citocinas proinflamatorias es un mecanismo por el cual la periodontitis puede relacionarse con la enfermedad de Alzheimer. Además, el tratamiento temprano de la enfermedad periodontal puede prevenir el desarrollo de la enfermedad de Alzheimer. Consideraciones finales: Por lo tanto, esta revisión muestra que la enfermedad de Alzheimer y la periodontitis pueden tener una relación patogénica, sin embargo, es necesario realizar más estudios para que este hecho se establezca científicamente.

Palabras clave: Enfermedad de Alzheimer, Periodontitis, Bacterias, Inflamación.

\section{INTRODUÇÃO}

O aumento da esperança média de vida da população tem proporcionado, de certa maneira, o aumento da prevalência de doenças relacionadas a idades mais avançadas. Dentre estas doenças, destacam-se as demências, como é o caso do Mal de Alzheimer, doença degenerativa e progressiva que se caracteriza pelo deterioramento emocional e cognitivo (BARREIROS ALBS, et al., 2006).

A Doença de Alzheimer foi descoberta em 1907 por Alois Alzheimer e vem sendo alvo de diversos estudos relacionados ao seu progresso e origem. Segundo a Organização Mundial da Saúde, a referida patologia darse independente de etnia, raça, nível socioeconômico e região geográfica, afeta uma parcela de $5 \%$ da população entre as idades de 65 aos 74 anos, sendo mais provável o seu desenvolvimento a partir dos 85 anos de vida. A doença, após diagnosticada, resulta na morte do afetado em torno de 8 a 15 anos, não sendo essa margem de tempo invariável (BARREIROS ALBS, et al., 2006).

Com o avanço da ciência e muitos esforços, acredita-se que a doença não resulta de um único motivo específico, mas sim de uma mistura de vários fatores, afetando assim cada indivíduo de uma forma diferente. Embora o fator de risco mais conhecido da doença seja a idade, outros fatores podem se associar para emersão da patologia. Apesar da existência de tratamentos, como o farmacológico, a doença ainda é irreversível, e estes tratamentos promovem apenas o abrandamento dos sintomas comportamentais (CAETANO LAO, et al., 2017).

Desse modo, estudos têm demonstrado relação entre o aparecimento do Alzheimer com a periodontite. Esta doença consiste em uma infecção bucal de característica multifatorial, causada por microrganismos gram-negativos, relacionada à má higiene bucal e a características imunológicas de cada indivíduo. A periodontite é caracterizada principalmente por perda óssea alveolar, sangramento, aumento da mobilidade dental e formação de edema gengival (RYDER MI, 2020).

Diante do exposto, o presente estudo teve como objetivo estimular e encorajar a comunidade científica a desenvolver mais estudos sobre a relação do desenvolvimento do Alzheimer a partir da periodontite, levando em consideração a abordagem da fisiopatologia, bem como avaliando possíveis métodos de tratamento do processo.

\section{REVISÃO BIBLIOGRÁFICA}

A Doença de Alzheimer possui uma gama de sintomas, dentre estes, os principais que emergem são os déficits de memória, que por sua vez geram ainda mais complicações devido ao fato de interferirem diretamente na capacidade do paciente executar suas tarefas diárias. A sintomatologia da enfermidade surge 
pelo fato de se tratar de uma doença neurodegenerativa, que por sua vez prejudicará funções cognitivas com apraxias construtivas, agnosias e distúrbios afásicos, habilidades motoras, surgimento de ideias delirantes, alucinações, apatia, agitação ansiedade, humor deprimido, euforia, desinibição, irritabilidade, perambulação, alterações sono/vigília, desordem alimentar e, como já citado, principalmente déficit de memória (CARVALHO KR, et al., 2008; DIOGUARDI M, et al., 2020).

Tangente ao citado, a Doença de Alzheimer pode ser dividida em 3 fases de acordo com a sua progressão. As fases estabelecidas são a leve, moderada e grave. As fases são acompanhadas desde os sintomas iniciais com perda de memória até as complicações motoras mais severas. Apesar de que na fase inicial os sintomas são julgados como sendo menos graves, não se deve carecer de preocupações e medidas devem ser tomadas urgentemente (CARVALHO PDP, et al., 2016).

Sendo assim, no primeiro estágio da moléstia o que mais prevalece entre todos os sintomas que podem surgir é a redução da capacidade da memória, esquecimentos, desorientações relacionadas ao espaço e tempo, perda de iniciativa na realização de tarefas e/ou tomada de decisões e espontaneidade, descaso com a própria aparência e complicações no trabalho. Também ocorre um gasto maior de tempo para a realização das tarefas do dia a dia, redução da atenção e concentração, dificuldades para lidar com pagamentos e dinheiro. Os indivíduos também podem apresentar carente senso crítico que resulta em tomadas de decisões equivocadas, além de alterações da sua personalidade, humor e elevação de sua agressividade, ansiedade e aparecimento de sinais de depressão (CARVALHO PDP, et al., 2016).

Quando se trata da fase moderada da doença, os problemas cognitivos ficam mais acentuados em relação à fase precedente. $O$ afetado começa a não conseguir mais realizar atividades instrumentais e atividades básicas da vida diária. Podem ocorrer também manifestações explosivas de sentimentos, como raiva, possuem dificuldade com o vocabulário tanto para falar quanto para leitura e escrita, dificuldades numéricas, escassez da capacidade de aprender novas coisas, pensamentos desarmônicos, choro, ansiedade, inquietação, agitação e redução da capacidade de se alinhar em situações inesperadas. Por fim, no terceiro momento da doença, o paciente normalmente perde integralmente sua independência, ficando acamado (ENGELHARDT E, et al., 2005; MEI F, et al., 2020).

Com base nisso, são necessário cuidadores permanentes. O paciente começa a apresentar problemas para deglutir, manifestações neurológicas, incontinência urinária e fecal, irritabilidade, mutismo e, por fim, morte. Entretanto, é necessário reiterar que os sintomas variam de doente para doente. Referente aos sentidos, o Mal de Alzheimer pode proporcionar danificações, sendo dificultado no sujeito a avaliação daquilo que ouve, prova, vê ou sente, apesar de que os órgãos relacionados com os sentidos estarem em bom estado de conservação (ENGELHARDT E, et al., 2005; MEI F, et al., 2020).

\section{Periodontite}

É um distúrbio inflamatório oral nos tecidos envoltórios dos dentes que resulta da instalação de microrganismos gram-negativos que podem produzir uma infecção local e sistêmica, causando edema, eritema, sangramento e ampliação da gengiva e que acomete cronicamente uma gama de indivíduos. $O$ tipo mais comum dessa patologia é a gengivite que afeta tanto crianças quanto adultos, atingindo de $30 \%$ a $90 \%$ e 40\% a 50\% nessas faixas etárias, respectivamente. A gengivite se não for tratada corretamente, pode evoluir para a periodontite que é o desaparecimento do tecido que liga osso ao dente (ligamento periodontal) devido à inflamação. Sendo assim, podemos afirmar que o aparecimento desses microrganismos e suas endotoxinas podem gerar uma resposta inflamatória muito grande com a produção de interleucinas e prostaglandinas, o que leva a um agravamento da inflamação, assim como a escovação de maneira errada e uso indevido do fio dental que contribuem diretamente para o desenvolvimento dessa patologia (FALCO A, et al., 2016).

\section{Fisiopatologia da Doença de Alzheimer}

No decorrer das últimas décadas, diversas hipóteses foram produzidas para explicar a fisiopatologia da Doença de Alzheimer. A mais antiga dentre as teorias é a colinérgica, formulada durante os anos $80 . \mathrm{Na}$ metade desta década, houve o surgimento da hipótese glutamatérgica. Além disso, em 1992, surgiu também 
a hipótese da "cascata amiloide". Decorrentes desta última conjectura, surgiram as hipóteses oligomérica e metálica (FONSECA SR, et al., 2008).

\section{A hipótese colinérgica}

Esta é a hipótese mais antiga para descrever a DA, e relaciona a doença com a diminuição na concentração de colina acetiltransferase (ChAT), enzima que tem como função a síntese de acetilcolina (ACh). A acetilcolina é um mediador químico de sinapses no sistema nervoso central (SNC), no sistema nervoso periférico e na junção neuromuscular. Essa diminuição na concentração é resultado da atrofia do núcleo basal de Meynert, que é a fonte produtora da enzima ChAT (FORLENZA OV, 2005).

Em situações normais, A ChAT é transportada para estruturas-alvo no sistema nervoso central: formação hipocampal, córtex cerebral e amígdala. Nestas regiões, ela catalisa a reação de síntese de ACh por meio de colina e acetilcoenzima A. Após a formação, a ACh é liberada na fenda sináptica, onde se acopla a dois tipos de receptores: muscarínico e nicotínico. A ação do ACh está envolvida no controle da função extrapiramidal, vestibular, em funções cognitivas como memória, aprendizado e atenção; em respostas emocionais, na modulação do estresse, no sono e na vigília (FORLENZA OV, 2005).

\section{A hipótese glutamatérgica}

A transmissão glutamatérgica forma o principal sistema excitatório no cérebro e desempenha um papel fundamental na fisiologia. O glutamato é fundamental na ativação de receptores metabotrópicos e três receptores ionotrópicos: N-metild-Aspartato (NMDA), do ácido a-amino-3-hidroxi-5-metil-4isoxazolepropiônico (AMPA) e de cainato. A superestimulação dos receptores NMDA pode levar a distúrbios de plasticidades e exocitotoxicidade, de forma que altere a homeostase de cálcio, aumentando a concentração intracelular deste eletrólito, podendo, assim, iniciar um processo de apoptose neuronal (FREITAS ICC, et al., 2008).

\section{A hipótese das placas neuríticas (cascata amiloide)}

A hipótese das placas neuríticas $\beta$-amiloides tem como base focos microscópicos de deposição extracelular de proteína beta-amiloide $(\mathrm{Ab})$ que ocorrem em forma de fibrilas amiloides, e, geralmente, as placas são encontradas no córtex límbico e no córtex de associação. Há o surgimento de neurites fisiológicas tanto dentro como ao redor do depósito amiloide. Estas alterações incluem lisossomos aumentados, numerosas mitocôndrias e filamentos helicoidais emparelhados. As placas são associadas intimamente a micróglias, expressando antígenoos de superfície associados à ativação, como CD45 e HLA-DR. A proteína beta-amiloide é originada da clivagem proteolítica da Proteína Precurosa Amiloide (APP) por ação de secretases (GEMELLI T, et al., 2013).

Em indivíduos saudáveis, a beta-amiloide é degradada por enzimas e retirada do encéfalo por um balanço de refluxo e influxo, mediado pela proteína receptora de LDL e também por receptores para produtos de glicosilaçao avançada.. Duas secretases, $\gamma$-secretase e $\beta$-secretase, são responsáveis por clivar o APP, originando peptídeo $A \beta$ em diferentes lugares, de forma que favoreça o depósito de proteína beta-amiloide. $\mathrm{Na}$ DA, uma relação desbalanceada entre a produção e a degradação leva ao depósito da proteína no córtex. Além disso, a superexpressão do gene APP, localizado no cromossomo 21, leva, quase que invariavelmente, à manifestação prematura da neuropatologia da DA. Assim, pessoas com Síndrome de Down apresentam características neuropatológicas clássicas da DA (GEMELLI T, et al., 2013).

\section{A hipótese oligomérica}

Estudos desenvolvidos durante a década de 90 verificaram que o peptídeo A $\beta$ é capaz de se agrupar em oligômeros solúveis. Se o $A \beta$ for obrigado a continuar em sua forma oligomérica, danifica as sinapses neurais, ocasionando a morte celular (HANE F e LEONENKO Z, 2014).

\section{A hipótese metálica}

Recentemente, novas evidências levaram à hipótese de que íons metálicos endógenos, como cobre e ferro, podem contribuir para a evolução de doenças neurodegenerativas, favorecendo a toxicidade e 
aumentando a agregação de $A B$, principalmente em meio aquoso. Esses biometais são capazes de produzir espécies reativas de oxigênio (EROs) e espécies reativas de nitrogênio (ERNs), e os danos causados por essas espécies são intensos: a oxidação de ferro gera anormalidades no RNA, diminuindo a síntese proteica, além de o radical hidroxila da EROs promover danos às biomoléculas de base nitrogenada e desoxirribose (HOERNKE M, et al., 2010).

\section{D.A e Periodontite}

Os mecanismos que envolvem completamente a fisiopatologia da periodontite em relação ao desenvolvimento do Alzheimer não são completamente conhecidos. Todavia, essa relação foi analisada com base em dois mecanismos, um acerca da inflamação sistêmica causada e outra embasada nos mecanismos fisiopatológicos das bactérias causadoras da periodontite (KAMER AR, et al., 2008; OLSEN I e SINGHRAO SK, 2020).

O primeiro mecanismo diz respeito a grande interação inflamatória das bactérias com as citocinas produzidas pelas células de defesa, que produzem IL-8, IL-1 $\beta$, IL-6, IL8, TNF- $\alpha$, PGE2 e a Proteína C Reativa (PCR). Em inflamações muito intensas, essas moléculas ganham a circulação causando uma inflamação sistêmica que posteriormente alcançará o cérebro. ${ }^{1}$ Além disso, essas citocinas derivadas da periodontite podem estimular fibras do nervo trigêmeo, levando ao aumento das citocinas cerebrais. Assim concluímos que essas citocinas atuam diretamente sobre as células nervosas, o que resulta em uma reação inflamatória amplificada para portadores/ da D.A e facilitando o desenvolvimento da doença em susceptíveis (KAMER AR, et al., 2008; OLSEN I e SINGHRAO SK, 2020).

O segundo mecanismo aborda sobre as características bacterianas que poderiam estar relacionados ao desenvolvimento da doença. Uma relação que demonstra que a associação de alguns tipos de bactérias à microbiota bucal pode estar intimamente ligada ao acometimento do Alzheimer é o fato de que as bactérias do gênero Treponema foram encontradas em 14 de 16 pessoas com a D.A e não foram encontradas em 14 de 18 pessoas que não possuem a D.A através da Reação em Cadeia Polimerase (RCP) (LUCAS CO, et al., 2013).

Relatos que não surpreendem desde a descoberta de Treponema denticola em cérebros de animais infectados laboratorialmente. As bactérias A. actinomycetemcomitans, $F$. nucleatum e a $P$. gingivalis estão sendo implicadas como bactérias que possivelmente desenvolveram a capacidade de invadir e causar a patologia cerebral. A P. gingivalis por exemplo, quando mortas e introduzidas subcutaneamente em ratos com encefalomielite autoimune mostraram um agravo na doença devido a inflamação estimulada pelo LPS que compõe parte da parede celular dessas bactérias e estimula receptores toll-like 2 e 4 das células humanas (LUCAS CO, et al., 2013).

O mecanismo pelo qual essas bactérias penetram no cérebro não é totalmente conhecido. No entanto, outros mecanismos descritos para o acesso de bactérias a outros locais diferente do foco da inflamação do periodonto podem ser possíveis, tais como o acesso das bactérias e das citocinas ao nervo trigêmeo e posteriormente ao córtex. Estudos clínicos definitivamente estão mostrando a relação das bactérias gramnegativas causadoras da periodontite com o desenvolvimento da doença de Alzheimer, no entanto, estudos ainda precisam ser produzidos para esclarecer de forma total os meios utilizados pelas bactérias para chegarem ou induzirem uma inflamação massiva do córtex (PARIKH V, et al., 2014).

\section{Tratamento}

A doença de Alzheimer é um distúrbio que afeta o indivíduo nos níveis neurofisiológico, psicológico e social. Através desse ponto de vista, o tratamento para os portadores da DA envolve terapias farmacológicas e psicossociais. No âmbito farmacológico, a principal droga no tratamento específico licenciada são os inibidores das colinesterases. O seu uso se deve ao fato de ocorrer uma diminuição colinérgica na DA. Tais medicamentos permitem uma maior disponibilidade colinérgica na fenda sináptica devido à inibição das enzimas acetilcolinesterase e butirilcolinesterase que degradam a acetilcolina (PARSONS CG, et al., 2007).

Entre os inibidores das colinesterases, existem a tacrina, galantamina, donepezil e rivastigmina. A tacrina é um inibidor reversível da acetilcolinesterase (AchE) e da buritilcolinesterase (BuChE) de curta duração. Já 
a galantamina é um inibidor reversível da AchE, de duração intermediária e o donepezil é inibidor reversível da acetilcolinesterase de longa duração. Por outro lado, a rivastigmina é um inibidor pseudo-irreversível tanto da AchE quanto da BuChE. Isso ocorre porque a interação da enzima com a rivastigmina na fenda sináptica leva a formação de um complexo carbamilado com a enzima, que impede a quebra da acetilcolina por inibição competitiva, porém reversível (FALCO A, et al., 2016).

A qualidade de vida, de acordo com a Organização Mundial da Saúde, compreende de maneira complexa a saúde física de um indivíduo, seu estado psicológico, suas relações interpessoais, sua fé e seu grau de dependência associados ao ambiente que o cerca. Ademais, a percepção que a pessoa tem de si mesma e as suas expectativas e preocupações também entram nessa definição. Nesse contexto, a DA, por ser um distúrbio neurodegenerativo acarreta, além dos danos neurológicos, complicações cognitivas e comportamentais. Sob essa perspectiva, o tratamento não farmacológico é constantemente recomendado devido às características complexas da doença e também porque é difícil de controlar a DA apenas com medicação (CAETANO LAO, et al., 2017).

Uma das principais consequências da doença de Alzheimer é a diminuição da autonomia dos pacientes. Isso leva a uma maior dependência de um cuidador, fato que se torna imprescindível na realização das necessidades básicas cotidianas. Muitas vezes, o indivíduo não consegue se vestir, comer e até mesmo cuidar da própria higiene. Nesse contexto, terapias como o método Kabat se tornam importantes e necessárias. Tal tratamento consiste na realização de exercícios de alongamento e mobilidade corporal que acarretam um aumento da flexibilidade articular amenizando rigidez e dor e também mantendo a amplitude do movimento. Todos esses fatores contribuem para a melhora da realização de atividades da vida diária (CAETANO LAO, et al., 2017).

Tendo em vista a hipótese da cascata amiloide, existem fármacos ainda em experimentação, com características antiamiloides. Os inibidores da fibrilogênese fazem parte dessa categoria de medicamentos. Dentre eles, destacam-se o clioquinol e o NC-531. Este impede a interação entre as glicosaminoglicanas e o peptídeo $\beta$-amiloide, com isso tem-se a diminuição das placas amiloides. Já o clioquinol é um quelante de cobre, ferro e zinco, formando complexos hidrossolúveis onde esses metais são envolvidos por tal agente. $O$ benefício dessa terapia reside no fato desses metais contribuírem para a formação das placas senis e a sua ação é neutralizada por meio desse medicamento. A neurotoxicidade do glutamato também é um problema que necessita de atenção. A memantina é um antagonista dos receptores NMDA e através disso ameniza a entrada de cálcio no neurônio o que diminui a ativação de caspases e a degradação neuronal (FALCO A, et al., 2016).

Por fim, tendo em vista a provável associação entre a Periodontite e o Alzheimer, medidas preventivas relacionadas à saúde bucal são imprescindíveis. Orientações quanto a uma adequada higiene bucal, visitas periódicas ao dentista são atitudes básicas, mas que podem gerar uma diminuição no risco de doença periodontal. Ademais, o tratamento precoce do quadro inflamatório reduz os riscos de maus prognósticos (DOMINY SS, et al., 2019).

\section{CONSIDERAÇÕES FINAIS}

De fato, é importante salientar que o Alzheimer possui uma complexa fisiopatologia e essa revisão acerca da associação entre DA e a Periodontite mostra que a doença bucal pode ser um fator de risco para desenvolvimento dessa síndrome demencial, porém, a verdadeira etiopatologia é desconhecida, pois pouca atenção tem sido voltada à explicação de como são desencadeados as reações inflamatórias e os mecanismos que explicam a migração das bactérias para o tecido nervoso. Mais evidências se fazem necessárias para determinar se a periodontite realmente pode causar essa neurodegeneração. Ademais, ao tratarmos da periodontite, uma afecção que acomete grande parte dos indivíduos, devemos levar em conta 0 seu potencial de risco para o desenvolvimento da DA. Assim, propomos o incentivo à realização de pesquisas por odontologistas e neurologistas para que estudos sejam realizados e o exato mecanismo envolvido no processo seja esclarecido para que políticas de controle e tratamento das doenças sejam estabelecidas e seguidas, assim, diminuindo a incidência da doença sobre a população. 


\section{REFERÊNCIAS}

1. BARREIROS ALBS, et al. Oxidative stress: Relations between the formation of reactive species and the organism's defense. Quimica Nova, 2006;29(1):113-23.

2. CAETANO LAO, et al. Alzheimer, sintomas e grupos: uma revisão integrativa. Vínculo, 2017;14(2):84-93.

3. CARVALHO KR, et al. O método Kabat no tratamento fisioterapêutico da doença de Alzheimer. Kairós Gerontologia, 2008;11(2):181-95.

4. CARVALHO PDP, et al. Tratamentos não farmacológicos que melhoram a qualidade de vida de idosos com doença de Alzheimer: Uma revisão sistemática. Jornal Brasileiro de Psiquiatria, 2016;65(4):334-9.

5. DIOGUARDI M, et al. The Role of Periodontitis and Periodontal Bacteria in the Onset and Progression of Alzheimer's Disease: A Systematic Review. Journal of Clinical Medicine, 2020;9(2):495.

6. DOMINY SS, et al. Porphyromonas gingivalis in Alzheimer's disease brains: Evidence for disease causation and treatment with small-molecule inhibitors. Science Advances, 2019;5(eaau3333):1-21.

7. ENGELHARDT E, et al. Treatment of Alzheimer's disease: Recommendations and suggestions of the Scientific Department of Cognitive Neurology and Aging of the Brazilian Academy of Neurology. Arquivos de Neuropsiquiatria, 2005;63(4):1104-12.

8. FALCO A, et al. Doença de Alzheimer: Hipóteses etiológicas e perspectivas de tratamento. Quimica Nova, 2016;39(1):63-80.

9. FONSECA SR, et al. Perfil neuropsiquiátrico na doença de Alzheimer e na demência mista. Jornal Brasileiro de Psiquiatria, 2008;57(2):117-21.

10. FORLENZA O V. Tratamento farmacológico da doença de Alzheimer. Revista de Psiquiatria Clínica, 2005;32(3):13748.

11. FREITAS ICC, et al. Convivendo com o portador de Alzheimer: perspectivas do familiar cuidador. Revista Brasileira de Enfermagem, 2008;61(4):508-13.

12. GEMELLI T, et al. Estresse Oxidativo como Fator Importante na Fisiopatologia da Doença de Alzheimer. Revista Brasileira Multidisciplinar, 2013;16(1):67.

13. HANE F, LEONENKO Z. Effect of metals on kinetic pathways of amyloid- $\beta$ aggregation. Biomolecules, 2014;4(1):10116.

14. HOERNKE $M$, et al. Influence of the hydrophobic interface and transition metal ions on the conformation of amyloidogenic model peptides. Biophysical Chemistry, 2010;150(1-3):64-72.

15. KAMER AR, et al. Alzheimer's Disease and Peripheral Infections: The Possible Contribution from Periodontal Infections, Model and Hypothesis. Journal of Alzheimer's Disease, 2008;13:437-49.

16. LUCAS CO, et al. A Doença De Alzheimer: características, sintomas e intervenções. Psicologia.pt, $2013 ; 1(1): 1-15$.

17. MEI F, et al. Porphyromonas gingivalis and its systemic impact: Current status. Pathogens, 2020;9(11):1-23.

18. OLSEN I, SINGHRAO SK. Interaction between genetic factors, Porphyromonas gingivalis and microglia to promote Alzheimer's disease. Journal of Oral Microbiology, 2020;12(1).

19. PARIKH V, et al. Interactions between $A \beta$ oligomers and presynaptic cholinergic signaling: Age-dependent effects on attentional capacities. Behavioural Brain Research, 2014;274:30-42.

20. PARSONS CG, et al. Memantine: a NMDA receptor antagonist that improves memory by restoration of homeostasis in the glutamatergic system - too little activation is bad, too much is even worse. Neuropharmacology, 2007;53(6):699723.

21. RYDER MI. Porphyromonas gingivalis and Alzheimer disease: Recent findings and potential therapies. Journal of Periodontology, 2020;91(S1):S45-9. 